\title{
Minimal to No Tongue Motion
}

National Cancer Institute

\section{Source}

National Cancer Institute. Minimal to No Tongue Motion. NCI Thesaurus. Code C127207.

A finding of minimal to no tongue motion during swallowing. 